\title{
Short communication: Evidence for methylglyoxal-mediated browning of Parmesan cheese during low temperature storage
}

\author{
R. D. Divine, ${ }^{*}$ D. Sommer, † A. Lopez-Hernandez, $\neq$ and S. A. Rankin ${ }^{1}$ \\ *Department of Food Science, Cornell University, Ithaca, NY 14853 \\ †Center for Dairy Research, and \\ $\ddagger$ Department of Food Science, University of Wisconsin, Madison 53706
}

\section{ABSTRACT}

Brown pigmentation can occasionally form in Parmesan cheese during the ripening process, creating an unappealing appearance and associated off-flavors. The browning reactions proceed at refrigerated temperatures and in the relative absence of reducing sugar, contrary to typical Maillard browning. Residual sugars, lipid oxidation products, byproducts of fermentation, and (or) enzymes may react with primary amines in cheese to form brown pigmentation and concomitantly generate volatile compounds unique to each of these reactions. Determining the volatile profiles provides a means of understanding the potential substrates involved and causative reaction pathways. This work is divided into 2 segments. The first portion characterized the pigmentation and the browning index of Parmesan cheeses with and without extensive browning. The second phase examined the volatile character of the cheeses using gas chromatography-mass spectrometry. Various pyrazines, such as 2,3,5-trimethylpyrazine and 3,5-diethyl-2-methylpyrazine, were found in the brown cheeses but were not present in the white samples. The formation of pyrazines is proposed to result from the spontaneous condensation of aminoacetone. Aminoacetone can be formed by the Strecker degradation of amino acids with methylglyoxal, the latter a byproduct of sugar fermentation. Evidence is provided to support a browning pathway mediated by the production of methylglyoxal in Parmesan cheese.

Key words: alkylpyrazine, browning, methylglyoxal, Parmesan

\section{Short Communication}

Parmesan cheese can develop undesirable brown discoloration (Figure 1) and concomitant off-flavors during the aging process (Demarigny et al., 2005). This brown

Received August 11, 2011.

Accepted January 7, 2012.

${ }^{1}$ Corresponding author: sarankin@wisc.edu discoloration appears late in the storage life (e.g., 10 mo, M. E. Johnson, University of Wisconsin-Madison, personal communication) of Parmesan cheese, well after residual milk sugars have been metabolized to trace levels (Gopal and Richardson, 1996; Demarigny et al., 2005) and at relatively low storage temperatures (e.g., $16^{\circ} \mathrm{C}$ ). Browning at such temperatures is atypical of Maillard reactions that proceed slowly below $80^{\circ} \mathrm{C}$ (Martins, 2003). The dark pigmentation and volatiles produced during browning processes adversely affect the appearance, texture, flavor, aroma, and economic value of Parmesan cheese (Demarigny et al., 2005). Although it has been shown that the presence of methylglyoxal in Parmesan cheese can cause low temperature browning (LTB), the chemistry of such a reaction is not documented in the scientific literature (McDonald, 1992; Urbach, 1995). This work proposes a chemical pathway based on the production of methylglyoxal as a means of better understanding and thus controlling this detrimental outcome.

Typical Maillard reactions involve the reaction of a primary amine and a carbonyl group. Commonly, protein provides the amine group, and reducing sugars, such as residual lactose or galactose, provide the carbonyl group (Friedman, 1996). Several intermediates may be formed before aroma-active and pigmented advanced glycation end products (AGE) are produced. Some AGE have functional qualities that can negatively influence the food's safety, nutrition, appearance, texture, and flavor (Friedman, 1996). Maillard browning is favored at high temperatures, usually in the range of $80^{\circ} \mathrm{C}$ to $120^{\circ} \mathrm{C}$, with reaction rates varying based on different reducing sugars and proteins (Martins, 2003). Other conditions that favor Maillard browning include water activity $\left(\mathrm{a}_{\mathrm{w}}\right)$ in the range of 0.5 to 0.75 (Pereyra Gonzales et al., 2010); neutral or weakly alkaline $\mathrm{pH}$ (Kwak et al., 2005); and a high sugar to protein weight ratio, generally above 0.05:1 (Kato et al., 1986).

Conditions of Parmesan cheese aging make typical Maillard browning unfavorable. Reducing sugar is an important reactant in the Maillard reaction (Figure 2a), and the absence of sugar leads to decreased production 


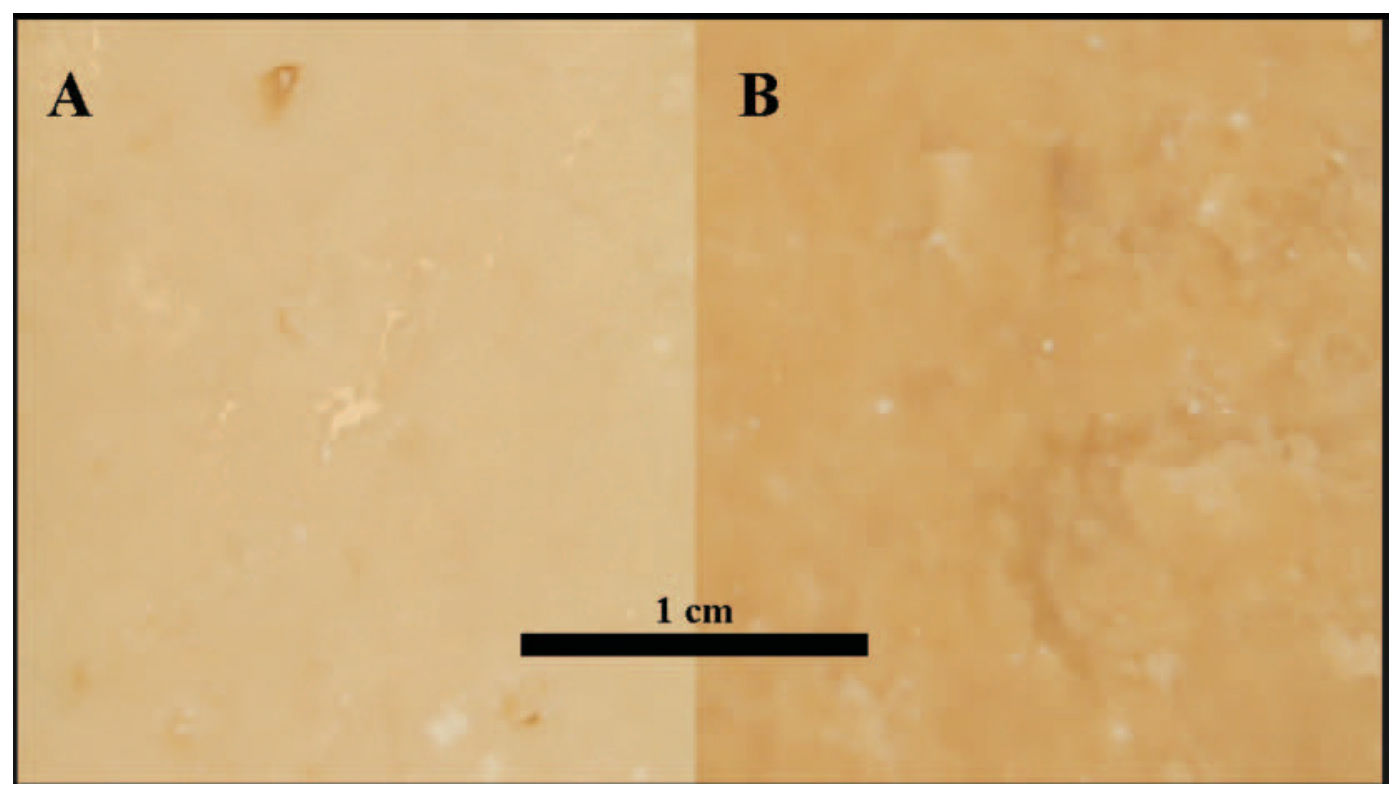

Figure 1. Visual reference for color difference between a white Parmesan cheese (A) and a brown Parmesan cheese (B). Lower L* values and higher $\mathrm{a}^{*}$ and $\mathrm{b}^{*}$ values correspond to increased brown pigmentation. Average $\mathrm{L}^{*}$ (lightness) values were 82.3 and 74.6 ; $\mathrm{a}^{*}$ (red-green) values were 4.67 and 10.4; and $\mathrm{b}^{*}$ (yellow-blue) values were 26.7 and 30.62 for the A and B samples, respectively. Color version available in the online PDF.

of AGE (Kato et al., 1986). Because lactose is fermented into various metabolites by starter and nonstarter bacteria during manufacture and aging, residual sugar is lowered to undetectable levels within a few months (Gopal and Richardson, 1996; Demarigny et al., 2005). Parmesan cheese is ripened at approximately $16^{\circ} \mathrm{C}$ for anywhere between 10 and 24 mo (Kosikowski and Mistry, 1997). The relative absence of reducing sugar and the low temperatures at which Parmesan cheese is ripened suggest that a nonsugar chemical pathway is responsible for the LTB.

Brown pigmentation and concomitant volatile production may arise by several pathways. Although the exact chemistry of brown melanoidin pigments is often complex and difficult to characterize, different browning pathways will also yield side reactions resulting in unique volatile profiles. Typical sugar-amine Maillard browning reactions can produce numerous volatiles such as furans, pyrroles, and (or) imines, among others (Smith et al., 1994; Nursten, 2005). The general forms of these reactions are shown using generic sugar and protein structures (Figure 2a). An alternative chemical pathway involves lipid oxidation-based carbonyl compounds interacting with amine groups, such as epoxyeneheptanal reacting with lysine to form n-alkylpyrroles (Figure 2b; Hidalgo and Zamora, 1995; Friedman, 1996). A third possible reaction occurs between protein amine groups and carbonyls formed during fermentation such as diacetyl, glyoxal, or methylglyoxal (Figure 2c; Rizzi, 1972). Finally, the enzyme polyphenol oxidase reacts with tyrosine to form several intermediates, which can then form brown nonvolatile melanins and volatile dehydro-L-ascorbic acid (Friedman, 1996; Figure 2d).

Because each of these reactions generates unique volatile compounds, the volatile profiles can provide evidence of the pathways and substrates involved. We hypothesize that residual sugar, oxidized lipids, fermentation metabolites, or enzymatic activity is providing the carbonyl group necessary to react with the amine in a novel, low-temperature process. The distinctive volatiles produced will support a given browning mechanism responsible for LTB in Parmesan cheese.

As a means of characterizing the color and extent of browning, colorimetry and browning indexes (BI) were determined. Eight different Parmesan cheeses were selected from 4 different manufacturers in the Midwest region of the United States for the purposes of this study. The cheeses were specifically chosen to represent either white $(\mathrm{n}=4)$ or brown $(\mathrm{n}=4)$ samples and all were between 10 and 14 mo of age. Each cheese met compositional and aging requirements of Parmesan cheese for legal sale in the United States. Approximately $50 \mathrm{~g}$ of each cheese was ground in a blender for $20 \mathrm{~s}$. Color was measured using the CIE Lab method, which captures $\mathrm{L}^{*}$ (lightness), a* (red-green), and $\mathrm{b}^{*}$ (yellow-blue) values. Samples were tested in triplicate (Colorflex $45^{\circ} / 0^{\circ}$ colorimeter with a $1.25-\mathrm{cm}$ diameter aperture; Hunter Lab, Reston, VA). Lower $\mathrm{L}^{*}$ values and higher $\mathrm{a}^{*}$ and $\mathrm{b}^{*}$ values correspond to increased brown pigmentation. Mean comparisons were done us- 
a)

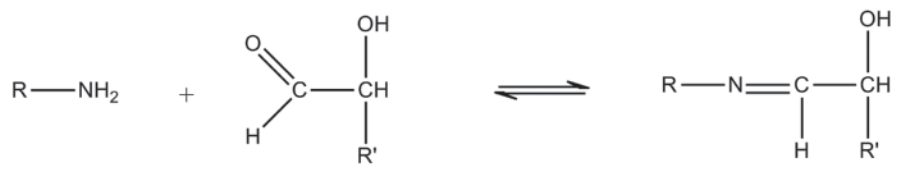

$\mathrm{R}=$ protein side chain $\quad \mathrm{R}^{\prime}=$ remainder of the reducing sugar

Schiff Base
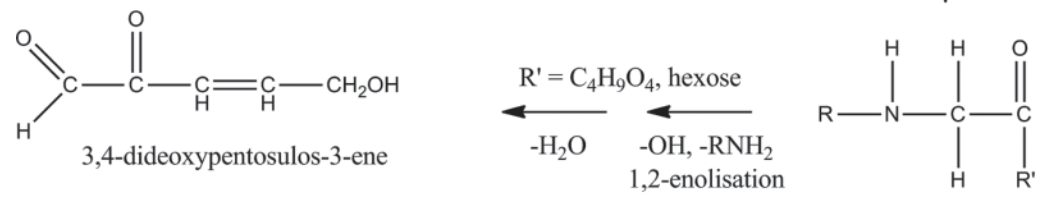

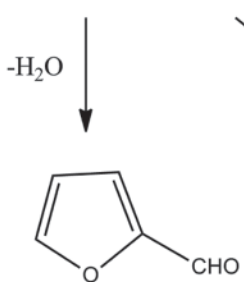

furfural
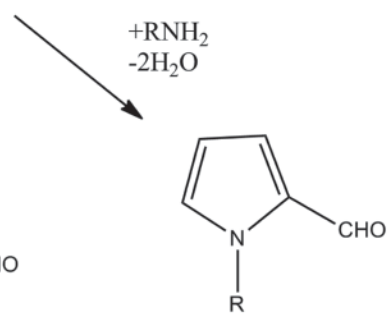

N-substituted pyrrole-2-aldehyde
Amadori Product

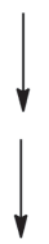

Imines, Furans, Pyrroles, Pyrimadines

b)

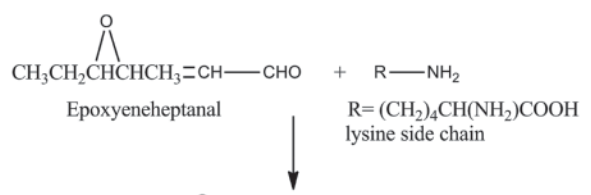

八

$\mathrm{CH}_{3} \mathrm{CH}_{2} \mathrm{CHCHCH}_{3}=\mathrm{CHCH}=\mathrm{N}-\mathrm{R}$
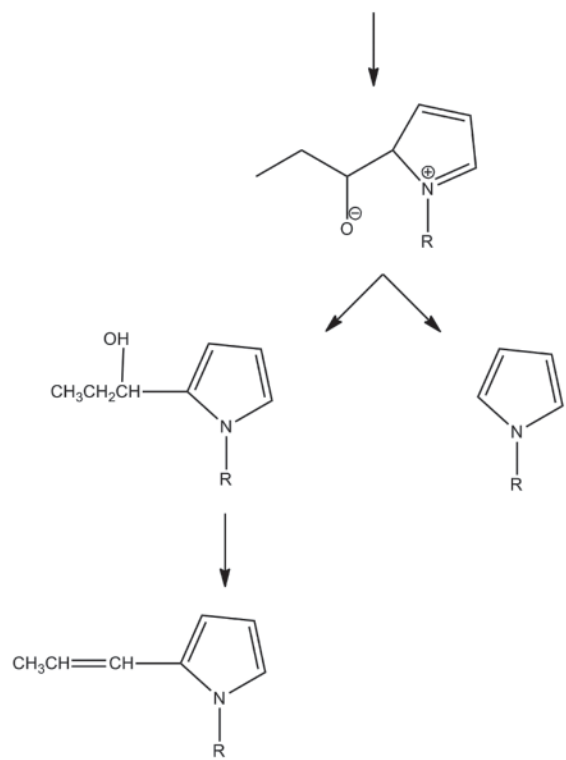

N-alkyl pyrroles

Figure 2. Hypothesized volatile browning end products. (a) General form of sugar-protein interaction, showing the volatile furans and pyrroles that can result (Smith et al., 1994; Nursten, 2005); (b) example of a lipid oxidation product browning reaction with epoxyeneheptanal reacting with lysine to form $\mathrm{N}$-alkyl pyrroles (Hidalgo and Zamora, 1995; Friedman, 1996); (c) reaction of several diketones with primary amines to represent interaction between fermentation products and protein (Rizzi, 1972); (d) enzymatic hydroxylation of tyrosine to DOPA, which can then produce nonvolatile melanins or react with L-ascorbic acid to form dehydro-L-ascorbic acid (Friedman, 1996). 


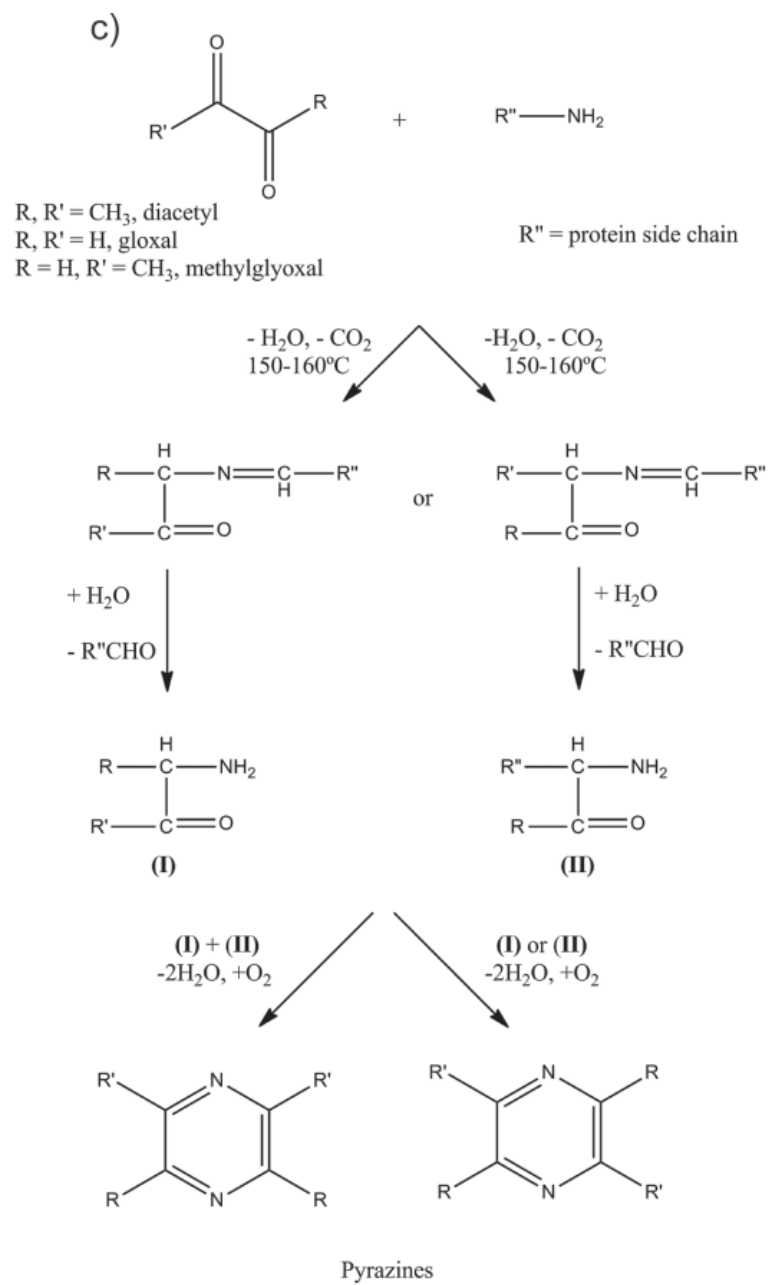

d)

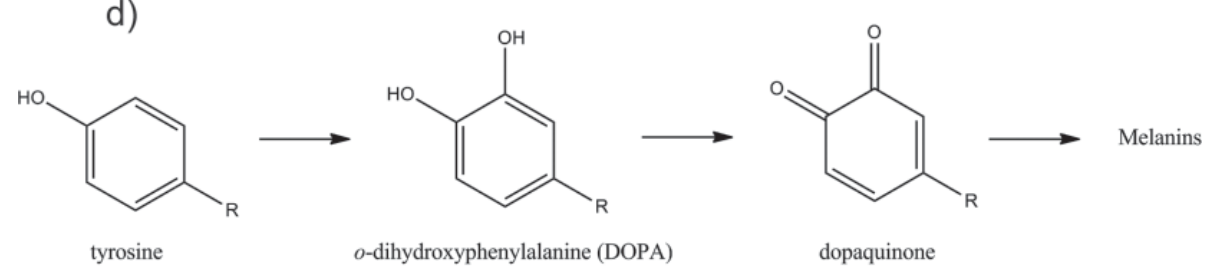

$\mathrm{R}=\mathrm{CH}_{2} \mathrm{CH}(\mathrm{COOH}) \mathrm{NH}_{2}$ tyrosine side chain<smiles>[R]C1=CC(=O)C(=O)C=C1</smiles>

DOPA

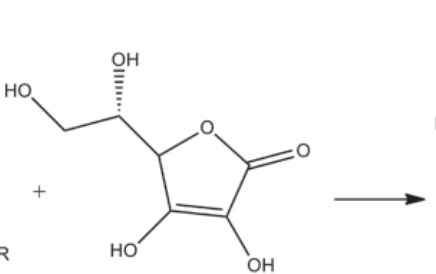

L-ascorbic acid

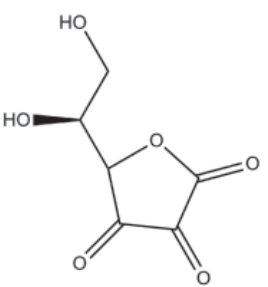

dehydro-L-ascorbic acid

Figure 2 (Continued). Hypothesized volatile browning end products. (a) General form of sugar-protein interaction, showing the volatile furans and pyrroles that can result (Smith et al., 1994; Nursten, 2005); (b) example of a lipid oxidation product browning reaction with epoxyeneheptanal reacting with lysine to form N-alkyl pyrroles (Hidalgo and Zamora, 1995; Friedman, 1996); (c) reaction of several diketones with primary amines to represent interaction between fermentation products and protein (Rizzi, 1972); (d) enzymatic hydroxylation of tyrosine to DOPA, which can then produce nonvolatile melanins or react with L-ascorbic acid to form dehydro-L-ascorbic acid (Friedman, 1996). 
ing statistical software (JMP Vs. 7.0.1, SAS Institute Inc., Cary, NC) using $\alpha<0.05$.

Browning index provides a spectrophotometric means of determining the degree of browning as the difference in optical density at $420 \mathrm{~nm}$ and $550 \mathrm{~nm}$ of enzymatic digests. The BI assessments were made using a procedure developed by Palombo et al. (1984) and modified as follows. A sample $(0.33 \mathrm{~g})$ of each cheese was placed into a $15-\mathrm{mL}$ test tube with $1.5 \mathrm{~mL}$ of distilled water. Then, $0.4 \mathrm{~mL}$ of protease solution, at a ratio of $1 \mathrm{mg}$ of protease (from Streptomyces griseus Type XIV, SigmaAldrich, St. Louis, MO) and $0.55 \mathrm{mg}$ of $\mathrm{CaCl}_{2}$ in $1 \mathrm{~mL}$ of Tris buffer at $\mathrm{pH}$ 7.0, was added. The test tubes were placed in an incubator at $45^{\circ} \mathrm{C}$ for $18 \mathrm{~h}$ and then cooled to $25^{\circ} \mathrm{C}$. Finally, $0.150 \mathrm{~mL}$ of $100 \%$ TCA ( $5 \mathrm{~g}$ of TCA dissolved in $2.3 \mathrm{~mL}$ of distilled water) was added. The resulting solution was centrifuged at $6,300 \times g$ for 20 min and gravity filtered (Whatman No. 1 filter paper). Samples were placed in a $1-\mathrm{mL}$ cuvette with a $1-\mathrm{cm}$ path length for analysis. A spectrophotometer (Shimadzu Scientific Instruments, Kyoto, Japan) was used to determine the absorbance at $420 \mathrm{~nm}$ (brown pigment absorbance) and $550 \mathrm{~nm}$ (protein absorbance). These values were used to calculate the $\mathrm{BI}$ of the sample $(\mathrm{n}=$ 3) as $\mathrm{A}_{420 \mathrm{~nm}}-\mathrm{A}_{550 \mathrm{~nm}}$ (Palombo et al., 1984).

Volatile profiles were determined using GC-MS with solid-phase microextraction. Cheese samples were heated at $40^{\circ} \mathrm{C}$ for $20 \mathrm{~min}$. Volatiles were trapped using a 1-cm polydimethylsiloxane (PDMS)/Carboxen solidphase microextraction fiber (Supelco, Bellefonte, PA). The gas chromatograph (Agilent 6890N, Agilent Technologies Inc., Palo Alto, CA) was fitted with a fused-silica capillary column $(\mathrm{RTx}-5 \mathrm{MS}, 30 \mathrm{~m}$ long $\times 0.025 \mathrm{~mm}$ i.d. $\times 0.05 \mu \mathrm{m}$ film thickness; Restek Corp., Bellefonte, PA) and paired with a mass selective detector (Agilent 5973 MS, Agilent Technologies Inc.). The initial temperature of the front inlet was $220^{\circ} \mathrm{C}$ at a flow of 33.9 $\mathrm{mL} / \mathrm{min}$. The sample was purged at $30.0 \mathrm{~mL} / \mathrm{min}$ with a preliminary holding time of $4 \mathrm{~min}$, using helium as the carrier gas. The oven temperature started at $40^{\circ} \mathrm{C}$ and increased by $10^{\circ} \mathrm{C} / \mathrm{min}$ for $14 \mathrm{~min}$ to a final temperature of $180^{\circ} \mathrm{C}$. Chemstation Software (Rev. D.02.00 SP1, Agilent Technologies Inc.) was used to identify the volatiles by matching (minimum $75 \%$ match) the mass spectra with a published database (National Institute of Standards and Technology, version 1.7 mass spectral database, Agilent Technologies Inc.). Each sample was run in duplicate. The limit of detection was estimated to be approximately $0.5 \mu \mathrm{g} / \mathrm{g}$ based on peaks heights of known concentrations of authentic standards at least 2-fold higher than the chromatographic baseline.

Compounds were regarded as tentatively identified by comparison to a mass spectral database and positively identified by further comparison to retention times of purchased standards. Chemical standards were purchased from Sigma-Aldrich (St. Louis, MO), and HPLC-grade water (Fisher Scientific, Chicago, IL) was used for dilutions. Mass spectra are reported for specific compounds for which a standard was not available (Figure 3).
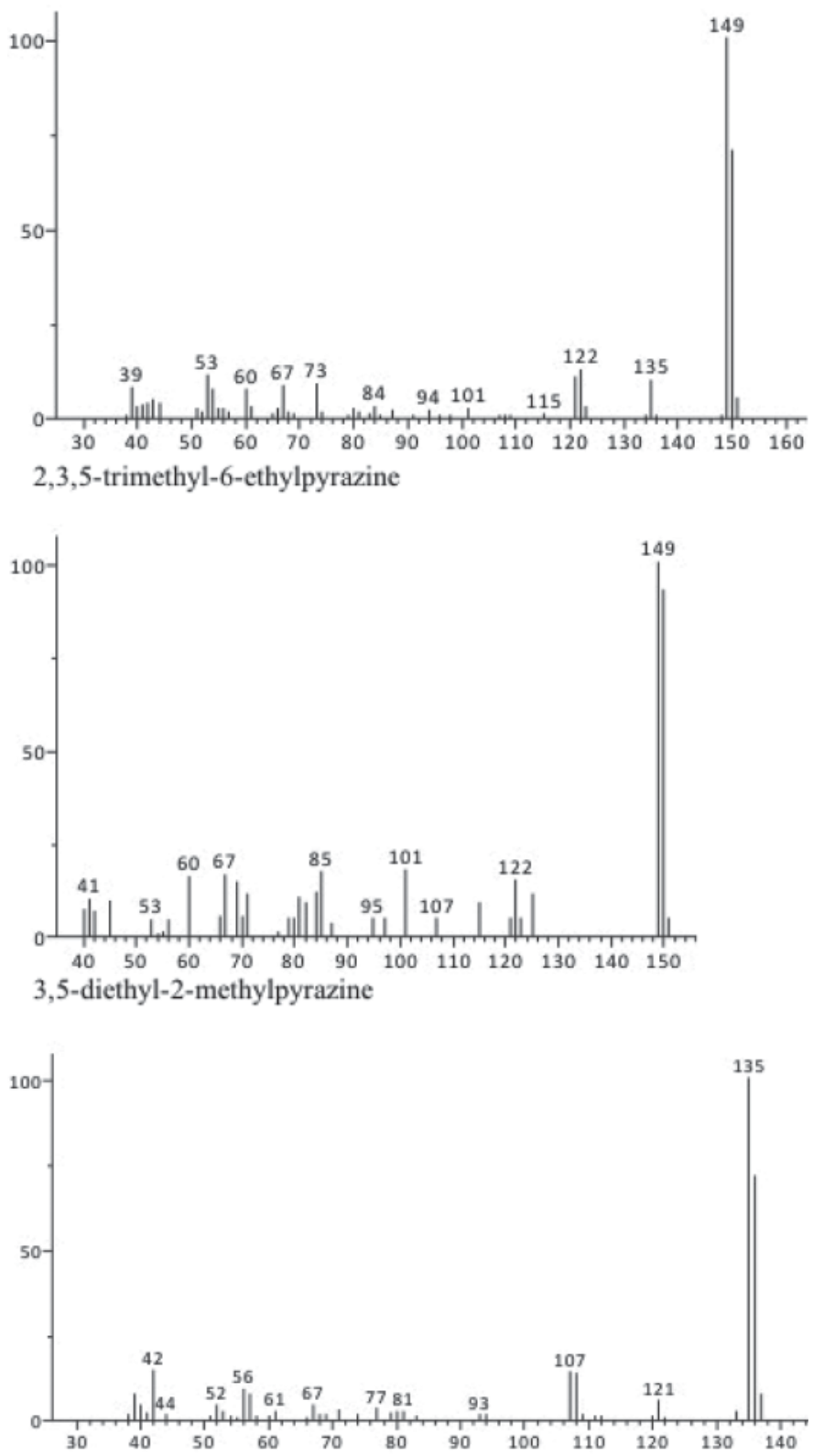

3-ethyl-2,5-dimethylpyrazine

Figure 3. Mass spectra of tentatively identified pyrazine products. The 5 largest peaks (with relative intensities in parentheses) for each compound are as follows: 2,3,5-trimethyl-6-ethylpyrazine: 149 (999), 150 (701), 122 (128), 53 (111), 121 (108); 3,5-diethyl-2-methylpyrazine: 149 (999), 150 (923), 101 (177), 85 (175), 67 (163); and 3-ethyl-2,5dimethylpyrazine: 135 (999), 136 (711), 42 (145), 107 (139), 108 (136). 
Table 1. Colorimetry ${ }^{1}$ and browning index (BI) values for white and brown Parmesan cheeses

\begin{tabular}{lrrrl}
\hline Sample & $\mathrm{L}^{*}$ & $\mathrm{a}^{*}$ & $\mathrm{~b}^{*}$ & $\mathrm{BI}$ \\
\hline White cheese & & & & \\
Mean & $83.2^{\mathrm{a}}$ & $2.75^{\mathrm{a}}$ & $23.3^{\mathrm{a}}$ & $0.097^{\mathrm{a}}$ \\
Range & 1.66 & 3.87 & 7.05 & 0.012 \\
SD & 0.86 & 1.58 & 3.36 & 0.006 \\
Brown cheese & & & & \\
Mean & $74.0^{\mathrm{b}}$ & $10.3^{\mathrm{b}}$ & $30.3^{\mathrm{b}}$ & $0.124^{\mathrm{b}}$ \\
Range & 4.11 & 3.82 & 4.02 & 0.069 \\
SD & 1.71 & 1.62 & 1.71 & 0.031 \\
\hline
\end{tabular}

${ }^{a, b}$ Means within a column with different superscripts are significantly different at the $\alpha<0.05$ level.

${ }^{1} \mathrm{~L}^{*}=$ lightness (where $100=$ white); $\mathrm{a}^{*}=$ red-green; $\mathrm{b}^{*}=$ yellow-blue. Lower $\mathrm{L}^{*}$ values and higher $\mathrm{a}^{*}$ and $\mathrm{b}^{*}$ values correspond to increased brown pigmentation.

The results of the colorimetry tests showed a large difference in the mean $\mathrm{L}^{*}, \mathrm{a}^{*}$, and $\mathrm{b}^{*}$ values in white and brown Parmesan cheese (Table 1). The average total color $(\mathrm{E})$ difference, calculated as $\Delta \mathrm{E}=\sqrt{ }\left[\left(\Delta \mathrm{L}^{*}\right)^{2}\right.$ $\left.+\left(\Delta \mathrm{a}^{*}\right)^{2}+\left(\Delta \mathrm{b}^{*}\right)^{2}\right]$, was 13.8. A color difference of 1.0 corresponds to the smallest visually perceptible change; thus, a value of 13.8 is regarded as a substantial change (Figure 1). White cheese had $\mathrm{L}^{*}$ values that averaged around 83 in the range of 82 to 84 , and brown cheese had $\mathrm{L}^{*}$ values that ranged from 71 to 76 with a mean near 74 . The brown cheese also exhibited mean higher $\mathrm{a}^{*}$ and $\mathrm{b}^{*}$ values (10.3 and 30.3 , respectively) than white cheese samples (2.75 and 23.3, respectively).

The spectrophotometric data similarly showed a significant difference between the brown and white cheeses (Table 1). The average BI was higher for brown cheese (0.124) than for white (0.097), indicating a larger concentration of nonenzymatic browning products (Palombo et al., 1984). These data are consistent with the colorimetry values (Table 1), as darker cheeses had a correspondingly high BI.

The majority of the volatile compounds found using GC-MS were present in all samples of cheese, including a variety of acids, alcohols, ketones, and others. These findings are consistent with previous research that documented the volatile character of Parmesan cheese using gas chromatography techniques, suggesting that such volatiles are characteristic of an average Parmesan cheese regardless of color (Qian and Reineccius, 2002). Several imines, pyrroles, and furans, which are characteristic of Maillard-type reactions (Figure 2a), were found in both types of Parmesan cheese at similar levels. $N$-Alkyl pyrroles were not found in any cheeses, suggesting that lipid oxidation product mechanisms are not responsible for the LTB (Figure 2b). No tyrosinederived compounds were identified, providing evidence against enzymatic browning (Figure 2d).

The notable volatile difference was the presence of various pyrazines in brown Parmesan cheeses (Table 2 ), whereas no pyrazines were found in any of the white cheeses. The compound 2,3,5-trimethylpyrazine was identified in every brown sample, whereas $2,3,5$-trimethyl-6-ethylpyrazine, 3,5-diethyl-2-methylpyrazine, and 3-ethyl-2,5-dimethylpyrazine were found in at least 2 brown samples. The compounds 2,6-dimethylpyrazine and tetramethylpyrazine were found in 1 sample each. These findings are consistent with previous research, as all of the pyrazine compounds, excluding 3,5-diethyl2-methylpyrazine, were previously identified by volatile analysis in Parmesan cheese (Qian and Reineccius, 2002). The pyrazines were reported to have baked, roasted, and nutty flavor characters (Qian and Reineccius, 2002). Although pyrazines have been found in other volatile studies of Parmesan cheese, this work links their presence as a co-product of brown discoloration.

Pyrazines have been synthesized in a laboratory setting, and several plausible pathways exist for pyrazine formation (Rizzi, 1972; Nursten, 2005; Guerra and Yaylayan, 2010). Guerra and Yaylayen (2010) suggest a pathway for pyrazine formation during Maillard browning using a glyoxylic acid-glycine system. The authors claim that these reactions are catalyzed at or above $150^{\circ} \mathrm{C}$, and thus do not align with the LTB phenomenon. Diketone-protein reactions can also produce some

Table 2. Qualitatively identified pyrazines (by GC-MS) unique to brown Parmesan cheese

\begin{tabular}{|c|c|c|c|c|c|}
\hline \multirow[b]{2}{*}{ Compound } & \multirow[b]{2}{*}{ Identification $^{1}$} & \multicolumn{4}{|c|}{ Sample $^{2}$} \\
\hline & & $\mathrm{A}$ & B & $\mathrm{C}$ & $\mathrm{D}$ \\
\hline 2,3,5-Trimethyl-6-ethylpyrazine & 1 & + & & + & \\
\hline $2,3,5$-Trimethylpyrazine & 1,2 & + & + & + & + \\
\hline 2,6-Dimethylpyrazine & 1,2 & & & + & \\
\hline 3,5-Diethyl-2-methylpyrazine & 1 & + & + & & + \\
\hline 3-Ethyl-2,5-dimethylpyrazine & 1 & & & + & + \\
\hline Tetramethylpyrazine & 1,2 & + & & & \\
\hline
\end{tabular}


2

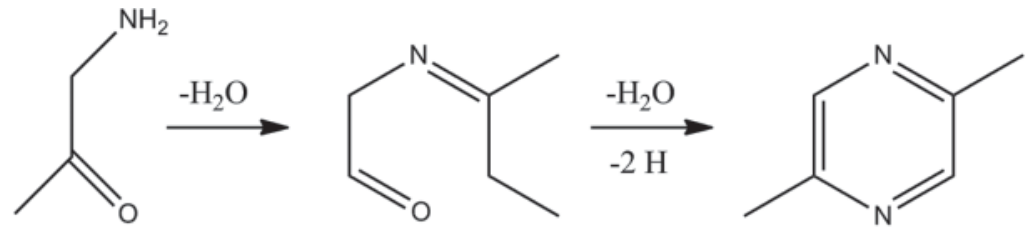

(I) aminoacetone

2,5 dimethylpyrazine
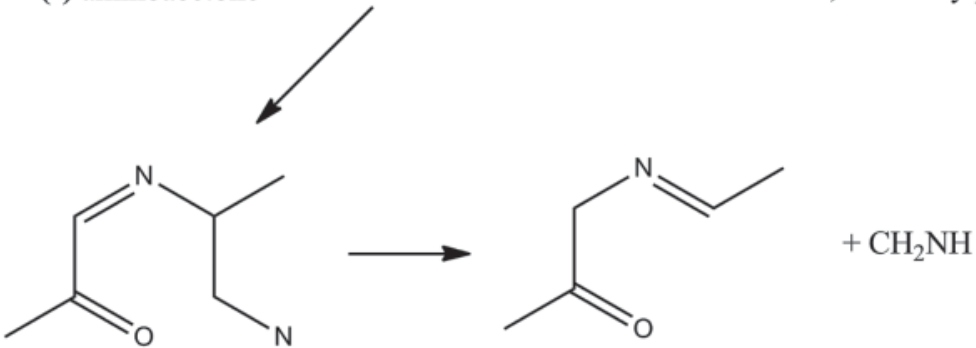

$+\mathrm{RCHO} \downarrow$
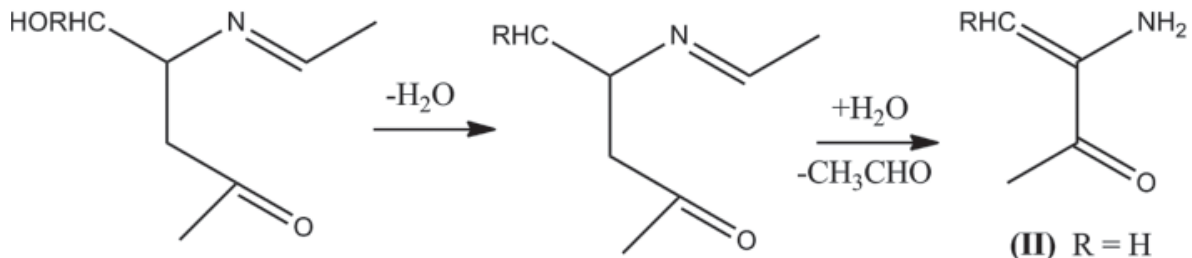

(II) $\mathrm{R}=\mathrm{H}$

(III) $\mathrm{R}=\mathrm{CH}_{3}$

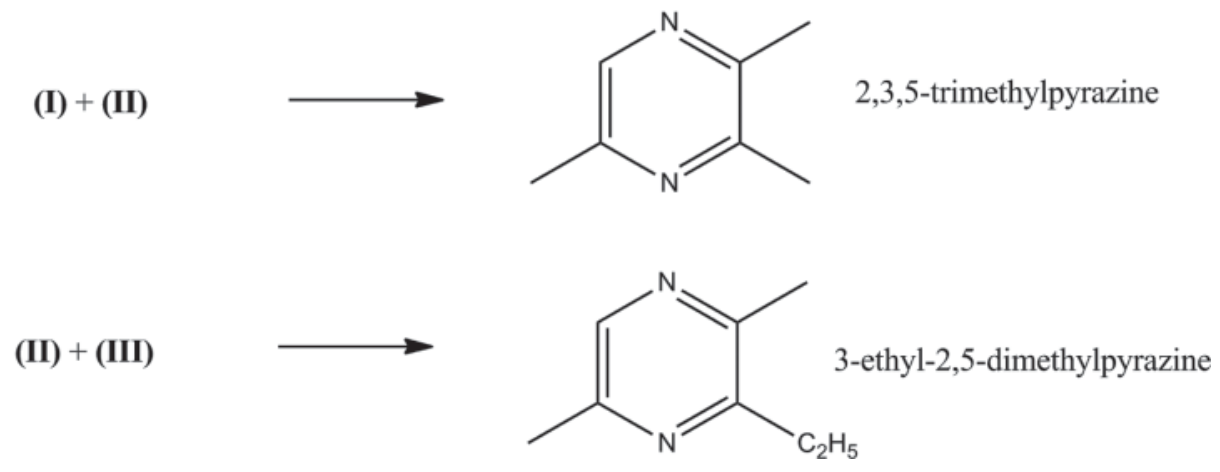

Figure 4. Formation of 2,3,5-trimethylpyrazine and 3-ethyl-2,5-dimethylpyrazine from an aminoacetone pathway (Rizzi, 1972; Nursten, 2005).

of the pyrazines observed in brown Parmesan cheese, such as tetramethylpyrazine (Figure 2c); however, these reactions were observed at 150 to $160^{\circ} \mathrm{C}$ and are also not congruent with LTB (Rizzi, 1972).

The most convincing pathway for LTB in Parmesan cheese involves the condensation of aminoacetone to form various pyrazines (Figure 4). It was observed that aminoacetone itself simultaneously condensed to form various pyrazine isomers, including 2,5-dimethylpyr- azine, 2,5-dimethyl-3-ethylpyrazine, and 2,3,5-trimethylpyrazine at $25^{\circ} \mathrm{C}$ (Rizzi, 1972). The primary route involves the condensation of 2 aminoacetone molecules to form 2,5-dimethylpyrazine. The formation of different pyrazines was explained by the isomerization of aminoacetone to form more stable intermediates before condensation, thus yielding alternate pyrazine structures. Because these reactions can occur at lower temperatures and without sugars present, it corresponds 


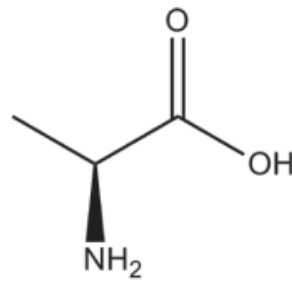

Alanine

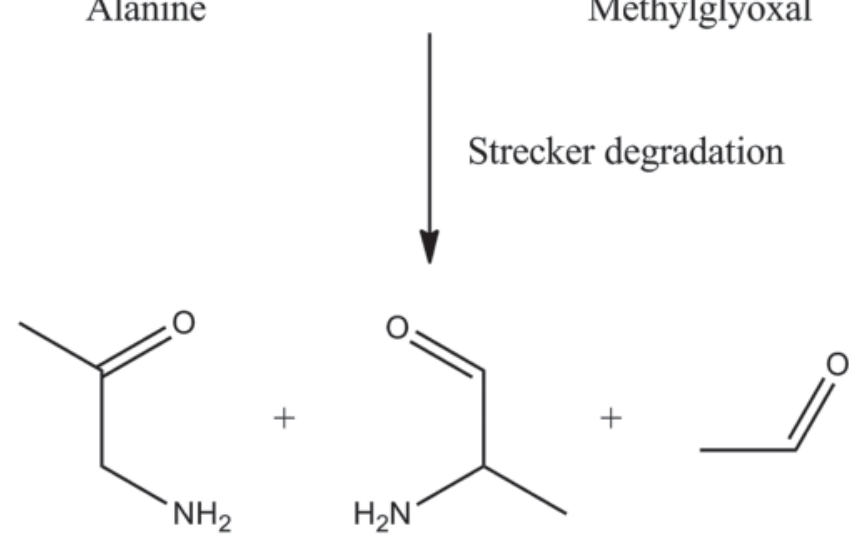

Aminoacetone

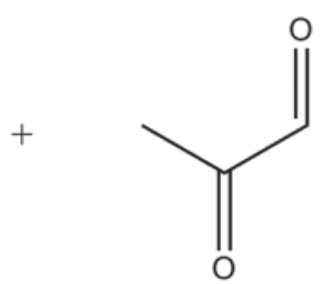

Methylglyoxal

\section{REFERENCES}

Belitz, H.-D., W. Grosch, and P. Schieberle. 2004. Food Chemistry. 3rd rev. ed. Springer-Verlag, Heidelberg, Germany.

Demarigny, Y., D. Hennequin, and D. Barillier. 2005. Utilisation of the experimental design methodology to reduce browning defects in hard cheeses technology. J. Food Eng. 68:481-490.

Friedman, M. 1996. Food browning and its prevention: An overview. J. Agric. Food Chem. 44:631-653.

Gopal, P. K., and R. K. Richardson. 1996. A rapid and sensitive method for estimation of galactose in Parmesan cheese. Int. Dairy J. 6:399-406.

Guerra, P. V., and V. A. Yaylayan. 2010. Dimerization of azomethine ylides: An alternate route to pyrazine formation in the Maillard reaction. J. Agric. Food Chem. 58:12523-12529.

Hidalgo, F. J., and R. Zamora. 1995. Characterization of the products formed during microwave irradiation of the nonenzymatic browning lysine/(E)-4,5-epoxy-(E)-2-heptenal model system. J. Agric. Food Chem. 43:1023-1028.

Kato, Y., T. Matsuda, N. Kato, K. Watanabe, and R. Nakamura. 1986. Browning and insolubilization of ovalbumin by the Maillard reaction with some aldohexoses. J. Agric. Food Chem. 34:351-355.

Figure 5. The Strecker degradation of alanine and methylglyoxal to form aminoacetone (Belitz et al., 2004).

well with the volatile analysis and the ripening conditions of Parmesan cheese. Aminoacetone can form by the Strecker degradation of alanine and methylglyoxal (Figure 5; Belitz et al., 2004). Methylglyoxal is produced by certain lactic acid bacteria, such as Lactobacillus bulgaricus, as a byproduct of sugar fermentation (Urbach, 1995). We propose that the condensation of aminoacetone derived from methylglyoxal is a plausible pathway for the formation of pyrazines and is potentially responsible for the LTB. These reactions are able to proceed in the temperature range for aging Parmesan cheese and are consistent with previous research that implicated methylglyoxal in the browning of Parmesan cheese (McDonald, 1992; Urbach, 1995).

Based on the temperature conditions, absence of residual sugar, and production of pyrazine compounds, this work provides chemical evidence for a methylglyoxal-mediated pathway for LTB in Parmesan cheese. This reaction involves bacterial metabolism of sugar to form methylglyoxal and spontaneous reactions to yield aminoacetone, the resulting brown pigmentation, and concomitant pyrazine formation. Although the spon-
Kosikowski, F. V., and V. V. Mistry. 1997. Cheese and Fermented Milk Foods. Vol. II: Procedures and Analysis. 3rd ed. F. V. Kosikowski LLC, Westport, CT.

Kwak, E. J., Y. S. Lee, M. Murata, and S. Homm. 2005. Effect of $\mathrm{pH}$ control on the intermediates and melanoidins of nonenzymatic browning reaction. Lebenson. Wiss. Technol. 38:1-6.

Martins, S. I. F. S. 2003. Unravelling the Maillard reaction network by multiresponse kinetic modelling. $\mathrm{PhD}$ Thesis. Wageningen University, Wageningen, the Netherlands.

McDonald, S. T. 1992. Role of $\alpha$-dicarbonyl compounds produced by lactic acid bacteria on the flavor and color of cheeses. PhD Thesis. University of Wisconsin, Madison.

Nursten, H. E. 2005. The Maillard Reaction: Chemistry, Biochemistry, and Implications. 1st ed. Royal Society of Chemistry, Cambridge, UK.

Palombo, R., A. Gertler, and I. Saguy. 1984. A simplified method for determination of browning in dairy powders. J. Food Sci. 49:1609-1613.

Pereyra Gonzales, A. S., G. B. Naranjo, G. E. Leiva, and L. S. Malec. 2010. Maillard reaction kinetics in milk powder: Effect of water activity at mild temperatures. Int. Dairy J. 20:40-45.

Qian, M., and G. Reineccius. 2002. Identification of aroma compounds in Parmigiano-Reggiano cheese by gas chromatography/olfactometry. J. Dairy Sci. 85:1362-1369.

Rizzi, G. P. 1972. A mechanistic study of alkylpyrazine formation in model systems. J. Agric. Food Chem. 20:1081-1085.

Smith, M. A., S. Taneda, P. L. Richey, S. Miyata, S. D. Yan, D. Stern, L. M. Sayre, V. M. Monnier, and G. Perry. 1994. Advanced Maillard reaction end products are associated with Alzheimer disease pathology. Proc. Natl. Acad. Sci. USA 91:5710-5714.

Urbach, G. 1995. Contribution of lactic acid bacteria to flavor compound formation in dairy products. Int. Dairy J. 5:877-903. 